\title{
BMJ Open High prevalence of HIV among men who have sex with men in Zhejiang, China: a respondent-driven sampling survey
}

Xiaohong Pan, ${ }^{1}$ Minni Wu, ${ }^{2}$ Qiaoqin Ma, ${ }^{1}$ Hui Wang, ${ }^{1}$ Wenzhe Ma, ${ }^{2}$ Shidian Zeng, ${ }^{3}$ Junfang Chen, ${ }^{4}$ Yan Zhang, ${ }^{5}$ Dandan Miao, ${ }^{2}$ Xin Zhou, ${ }^{1}$ Tingting Jiang, ${ }^{1}$ Lin He, ${ }^{1}$ Yan Xia, ${ }^{1}$ Zhihang Peng, ${ }^{2}$ Shichang $\mathrm{Xia}^{1}$

To cite: Pan X, Wu M, Ma Q, et al. High prevalence of HIV among men who have sex with men in Zhejiang, China: a respondent-driven sampling survey. BMJ Open 2015;5: e008466. doi:10.1136/ bmjopen-2015-008466

- Prepublication history for this paper is available online. To view these files please visit the journal online (http://dx.doi.org/10.1136/ bmjopen-2015-008466).

XP and MW contributed equally.

Received 10 April 2015 Revised 3 October 2015 Accepted 19 October 2015

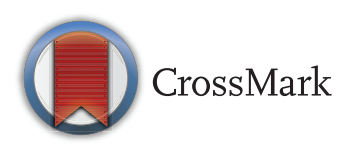

For numbered affiliations see end of article.

\section{Correspondence to} Dr Shichang Xia; shchxia@cdc.zj.cn

\section{ABSTRACT}

Objectives: To examine the prevalence of HIV and risk behaviours among men who have sex with men (MSM) and to explore the feasibility of using respondentdriven sampling in this population in order to conduct customised interventions among MSM in the future.

Design: Cross-sectional study.

Setting: Zhejiang, China.

Participants: 1316 MSM.

Primary and secondary outcome measures: HIV prevalence rates and factors associated with HIV infection; sociodemographic and behavioural information of participants, syphilis prevalence rates.

Results: The adjusted prevalence of HIV and syphilis were $13.8 \%$ and $11.4 \%$, respectively. Multivariate analysis showed that higher educational level, support treatment of HIV, negative syphilis are protective factors of HIV infection. MSM who had heterosexual behaviour before and whose primary sexual partner was HIV-positive were less likely to be infected with HIV compared with their counterparts, while frequency of sexual behaviour with primary sexual partner was positively associated with HIV infection.

Conclusions: This survey confirmed a high HIV prevalence among MSM in Zhejiang province. MSM are extremely vulnerable to HIV infection and comprehensive interventions are urgently needed to slow the spread of HIV among MSM.

\section{INTRODUCTION}

HIV transmission through homosexual behaviours is drawing more and more attention in recent years. Globally, 3-25\% of all HIV/ AIDS infections are transmitted via male homosexual behaviours, and this prevalence is much higher compared with regional adult HIV prevalence. ${ }^{1}$ In China, an estimated two to five per cent of all male adults are homosexual/bisexual, ${ }^{2}$ and the main transmission route of $\mathrm{HIV}$ in China has shifted from injection drug use to sexual

\section{Strengths and limitations of this study}

- Compared with other sampling methods, respondent-driven sampling (RDS) is a methodological advance for enrolling hidden subgroups through social networking.

- First large-scale cross-sectional study of HIV infection among men who have sex with men (MSM) in Zhejiang.

- Low coupon rate caused by potential reason leads to more consumption of time and resources.

- Data collected by RDS requires unique statistical techniques and may have operational difficulties in some situations.

- The focus of intervention now should be on the distinctions between adequate knowledge and risk behaviours among MSM.

transmission. ${ }^{3}$ Male homosexuality has received increased attention in recent years, because HIV transmission through homosexual behaviours increased from $0.3 \%$ before 2005 to more than $13.7 \%$ in $2011,{ }^{4} 5$ and $25.8 \%$ of new-found HIV infectors were infected through homosexuals in $2014 .^{6}$ With the same transferring routes, syphilis is also a biological factor associated with HIV infection $^{7}$ and a majority of men who have sex with men (MSM) with syphilis have been reported to be HIV-positive. ${ }^{8}$ Understanding the risk behaviours and sociodemographic characteristics of MSM helps in guiding evidence-based prevention efforts. ${ }^{9}$

Zhejiang, a coastal province located in the South-East with a total population of 54.49 million, is one of the most densely populated and economically vibrant provinces in China. Within this province, epidemics of HIV in MSM continue to expand. Between 2008 and 2011, data from sentinel surveillance described a steady increase in HIV 
seroprevalence from $4.4 \%$ to $8.6 \% .^{10} 11$ Among all the cities of Zhejiang province, Hangzhou, Ningbo and Wenzhou are the top three HIV epicentres; prevalence of HIV infection in these three cities were $8.71 \%, 8.97 \%$ and $9.23 \%$ in 2011, respectively, and became $12.3 \%$, $10.29 \%$ and $7.23 \%$, in $2013 .^{12}$

In order to effectively guide and evaluate prevention programmes, in-depth data on MSM are needed. Previous surveys have reported low HIV prevalence among MSM in China and age and frequency of sex were positively associated with the risk of HIV infection. ${ }^{13} 14$ However, because of the stigmatisation of homosexuality, MSM are hard to reach in China, thus, the participants of this research were recruited by using convenience sampling. Convenience sampling tends to recruit the most visible segments of a hidden population and may miss some subgroups that are not easily accessed, thus falling short of achieving a diverse sample. In addition, convenience surveys may be effected easily by bias and the final composition of the sample is heavily dependent upon the choice of seeds and short recruitment chains within their own social network. ${ }^{15}$ To overcome the difficulties of monitoring sexual risk and HIV prevalence in this population and to improve the representation of MSM samples, respondent-driven sampling (RDS) was used to access and recruit participants in recent studies. RDS is based on a long-chain referral recruitment strategy, which is thought to be advantageous in reaching the most hidden segments of already-hidden populations ${ }^{16}$ and has been adopted by public health researchers worldwide for sampling injecting drug users (IDUs), MSM and commercial sex workers successfully in China $^{1718}$ and other areas of the world. ${ }^{1920}$ This survey was conducted to examine the prevalence of HIV and risk behaviours among MSM and to explore the feasibility of using RDS in this population in order to conduct customised interventions among MSM in the future.

\section{MATERIALS AND METHODS}

\section{Participants}

Participants were eligible to be included in the study if they were male and had anal or oral sex with another man in the past 12 months; they also need to have resided in the study settings for more than 3 months at the time the study was conducted. Also, all participants admitted to the study were 14 years or older and participating in the study for the first time. Participants were excluded if they met any of the following situations: had difficulty providing informed consent because of intoxication, poor mental health or intellectual deficiency; did not complete the questionnaire and/or serology survey; did not have a valid coupon; or refused to participate for other reasons.

\section{Sampling method and participant recruitment}

RDS was used to recruit MSM eligible for the aforementioned criteria. The study was conducted at district-level
Centres for Disease control and prevention (CDCs) of each city, in Jiangbei district in Ningbo and Lucheng district in Wenzhou. In Hangzhou it was conducted at the Love Working Group of Zhejiang (a gay outreach organisation) in Xiacheng district. These cities were chosen for their similarity in economic level, population size and high prevalence of HIV, and also because they are located in Eastern, Southern and Northern Zhejiang, respectively. All survey sites were in the central areas of the cities. For each site, several initial participants (seeds) with high popularity and sociability among different subgroups were chosen purposively. The numbers of seeds were 8, 11 and 5 in Hangzhou, Ningbo and Wenzhou, respectively, among which 1 seed in Hangzhou and 2 seeds in Ningbo failed to recruit a secondary wave of participants. After giving informed consent, seeds were required to provide their personal information and blood samples for HIV and syphilis testing, and complete a questionnaire regarding demographic and behavioural information. Afterwards, each seed was given three coded coupons, which were valid for 1 month, to recruit any peers in his network. This process was repeated until the target sample size was achieved. Participants who completed the survey successfully were given a souvenir and a phone card valued $¥ 100$.

The sample sizes were calculated using the following equation:

$\mathrm{n}=\operatorname{Deff} \frac{\left[\left(Z_{1-(\alpha / 2)}+Z_{1-\beta}\right){\sqrt{\mathrm{P}_{\mathrm{A}, 1}\left(1-P_{A, 1}\right)+P_{A, 2}\left(1-P_{A, 2}\right)}}^{2}\right.}{\left(P_{A, 2}-P_{A, 1}\right)^{2}}$

where, Deff, design effect (range=1.25-2.0).

According to the research by Salganik ${ }^{21}$ with a design effect of 2.0, the sample size was set as 1316, distributed city-wise as follows: Hangzhou (511), Ningbo (351) and Wenzhou (454). The process of recruitment is shown in figure 1 .

\section{Tools and measurements}

Interviews were carried out using a self-designed questionnaire including basic information, sexual behaviours and networking, the Center for Epidemiologic Studies Depression Scale (CES-D), behavioural and sociocultural characteristics, history and willingness for HIV testing and attitude towards antiretrovirus treatment.

Basic information included sociodemographic characteristics, relation with the introducer and selfperceived physical condition. Sexual behaviours included ages of sex debut (homosexual and heterosexual, respectively), self-perceived sex orientation, venues to find partners and frequencies of sexual behaviour and condom use with male and female regular sexual partners, casual sexual partners and sex workers, respectively. Sexual networking was assessed by asking participants to recall no more than five of their male sexual partners during the past 12 months and rank them by sexual frequency, and then investigate the 


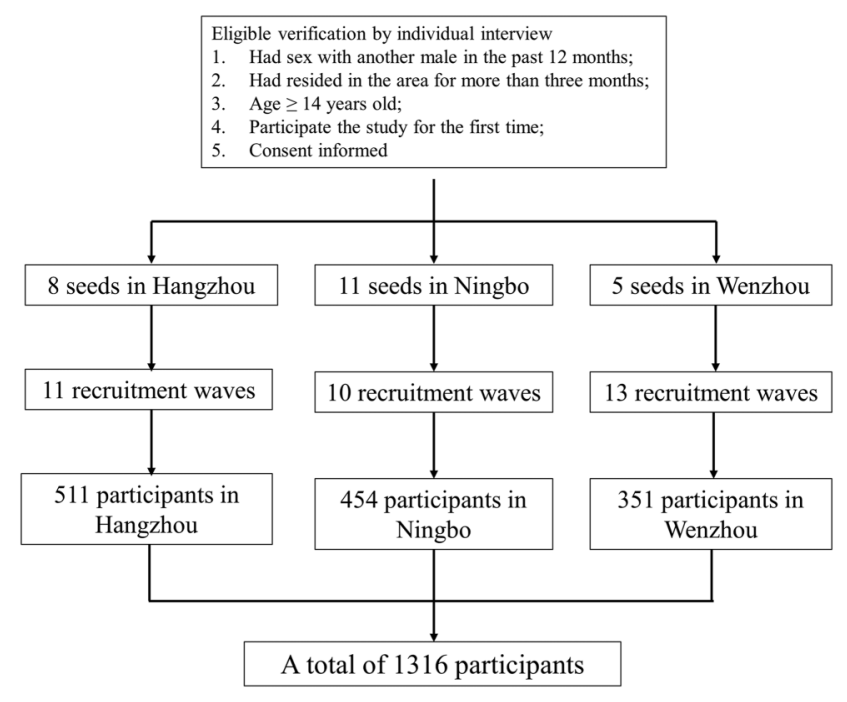

Figure 1 Public health challenges of the emerging HIV epidemic among men who have sex with men in China.

relationship with participant, age, sexual frequency and HIV status of these partners. Venues were classified into: (A) pubs, discos, tearooms or clubs; (B) bathhouses, saunas, pedicure centres or massage parlours; $(\mathrm{C})$ parks, public restrooms or lawns; (D) internet; (E) others.

CES-D was used to measure current level of the depressive symptomatology, and was made up of 20 items. $^{22}$ Behavioural section included description of smoking, drinking, drug using and HIV/sexually transmitted disease(STD) intervention, and sociocultural characteristics included suicidal tendency, homosexual violence, suffered sexual abuse in childhood, selfperceived possibility of HIV infection and effect of social attitude towards MSM on sexual behaviour. Smoking was defined as having at least one cigarette per day for more than 1 year or having 300 cigarettes or more in 3 months; drinking was defined as having more than 100 grams of alcohol per week.

\section{Quality control}

A preliminary investigation and field exercise had been conducted to ensure the success of the study. At each site there was a manager, a registration clerk, a laboratory technician, a quality control supervisor and several investigators, and all of them were well trained. After the qualification screening, participants signed a consent form and completed the questionnaire one-on-one with professional investigators. During recruitment, follow-up phone calls were made to improve the quality of the investigation. After several recruitment waves (11 in Hangzhou, 10 in Ningbo and 13 in Wenzhou), the major characteristics of the participants, including age, HIV and syphilis prevalence, tended to stabilise (the proportions of different options among these characteristics changed $<2 \%$ in a new recruitment wave compared with the previous one). In this sense, according to the RDS formulations, equilibrium was reached.

\section{Testing of HIV and syphilis}

Rapid tests for HIV were conducted using two ELISAs. If the result of one ELISA was positive, a western blot test was conducted for confirmation. Syphilis screening was performed by ELISA, and specimens testing positive for the syphilis antibody were confirmed by the Treponema pallidum particle agglutination test or toluidine red unheated serum test. For each participant in the study, pretest and post-test counselling were provided. Referral services were provided for HIV-positive or syphilispositive cases.

\section{Statistical analysis}

Questionnaire data were double-entered and then checked for accuracy using EpiData (V.3.1; The EpiData Association, Odense, Denmark). Microsoft Excel 2007 was used for checking the logicality of the data and supplementing any lost data. The analysis of RDS adjustment was produced by STATA (V.12.0 for Windows; StataCorp LP, College Station, USA) with RDS package, which was achieved by two steps of commands ('rds_network' to analyse the social network and 'rds' to produce the estimation of statistics such as adjusted proportions and weights). To identify factors associated with HIV infection, univariate and multivariate logistic regression analyses were also produced by STATA with the following regression model:

$$
\mathrm{g}\left(\theta_{i}\right)=x_{\mathrm{i}}^{\mathrm{T}} \beta+\omega_{\mathrm{i}}, \quad i=1,2, \ldots, \mathrm{n}
$$

Where $\omega_{i}$ is a latent effect of the network structure. ${ }^{23}$ Variables with $\mathrm{p}$ value $<0.2$ in univariate analysis were applied in multivariate analysis to produce the final results.

\section{RESULTS}

\section{Demographic and sociocultural characteristics}

Sociodemographic characteristics of respondents are demonstrated in table 1 . Statistics show that the majority of participants $(72.90 \%)$ were between 20 years and 40 years of age, $69.46 \%$ of them had resided in the area for longer than 3 years and $71.93 \%$ were under a social health insurance system. Occupations represented included mainly company employees (47.99\%) and workers (25.49\%). Most participants (37.25\%) had monthly incomes over $¥ 4000$, and another sizeable proportion $(30.65 \%)$ had monthly incomes of $¥ 3000-3999$. Approximately half $(51.26 \%)$ were single and $30.81 \%$ were married. Among all participants, $84.71 \%$ had graduated from secondary school or above. Table 1 also shows that more than half of the invitations came from close friends and acquaintances $(32.77 \%$ and $26.40 \%$, respectively), which dovetails with the RDS methodology that recommendations depend on the social networking of MSM. A total of $92.0 \%$ (95\% CI $90.0 \%$ to $93.6 \%)$ of the social networks had fewer than 20 connections. 
Table 1 Sociodemographic characteristics of MSM

\begin{tabular}{|c|c|c|c|}
\hline Variable & $\mathbf{N}$ & $\begin{array}{l}\text { Crude } \\
\text { prevalence } \\
(\%)\end{array}$ & $\begin{array}{l}\text { Adjusted } \\
\text { prevalence } \\
(\%)\end{array}$ \\
\hline \multicolumn{4}{|l|}{ Age (years) } \\
\hline$\leq 20$ & 82 & 6.23 & 8.42 \\
\hline 21 to 30 & 571 & 43.39 & 41.90 \\
\hline 31 to 40 & 398 & 30.24 & 31.00 \\
\hline 41 to 50 & 182 & 13.83 & 12.65 \\
\hline$\geq 51$ & 83 & 6.31 & 6.02 \\
\hline \multicolumn{4}{|l|}{ Marital status } \\
\hline Cohabit with women & 44 & 3.35 & 5.18 \\
\hline Cohabit with men & 135 & 10.27 & 8.68 \\
\hline Single & 670 & 50.95 & 51.26 \\
\hline Married & 406 & 30.87 & 30.81 \\
\hline Divorced/widowed & 60 & 4.56 & 4.07 \\
\hline \multicolumn{4}{|c|}{ Duration of residence in Zhejiang (year) } \\
\hline$\leq 3$ & 679 & 52.72 & 30.54 \\
\hline$>3$ & 609 & 47.28 & 69.46 \\
\hline \multicolumn{4}{|l|}{ Insurance } \\
\hline Uninsured & 346 & 26.29 & 28.07 \\
\hline Insured & 970 & 73.71 & 71.93 \\
\hline \multicolumn{4}{|l|}{ Education level } \\
\hline $\begin{array}{l}\text { Primary school or } \\
\text { below }\end{array}$ & 44 & 3.51 & 5.56 \\
\hline Middle school & 135 & 10.76 & 9.73 \\
\hline $\begin{array}{l}\text { High school/ } \\
\text { secondary school }\end{array}$ & 670 & 53.39 & 56.79 \\
\hline College or above & 406 & 32.35 & 27.92 \\
\hline \multicolumn{4}{|l|}{ Monthly income (¥) } \\
\hline No income & 106 & 8.05 & 7.14 \\
\hline$\leq 1999$ & 72 & 5.47 & 5.74 \\
\hline 2000 to 2999 & 240 & 18.24 & 19.21 \\
\hline 3000 to 3999 & 424 & 32.22 & 30.65 \\
\hline$\geq 4000$ & 474 & 36.02 & 37.25 \\
\hline \multicolumn{4}{|l|}{ Occupation } \\
\hline Employee & 603 & 52.66 & 47.99 \\
\hline Businessman & 102 & 7.75 & 6.11 \\
\hline Worker & 300 & 22.80 & 25.49 \\
\hline Student & 46 & 3.50 & 4.45 \\
\hline Others & 175 & 13.30 & 15.96 \\
\hline \multicolumn{4}{|c|}{ Relationship with the introducer } \\
\hline Sexual partner & 53 & 4.09 & 5.10 \\
\hline Close friend & 486 & 37.53 & 32.77 \\
\hline Ordinary friend & 292 & 22.55 & 24.83 \\
\hline Acquaintance & 373 & 28.80 & 26.40 \\
\hline Stranger & 87 & 7.03 & 10.90 \\
\hline
\end{tabular}

\section{HIV and syphilis prevalence}

According to the serological test results, the crude prevalence of HIV was $15.2 \%$ and that of syphilis was $15.3 \%$, and the respective adjusted prevalences were $13.8 \%$ (95\% CI $11.7 \%$ to $16.9 \%$ ) and $11.4 \%$ (95\% CI $8.1 \%$ to $16.0 \%)$. Adjusted prevalence of HIV/syphilis co-infection was $4.9 \%$ (95\% CI $3.2 \%$ to $7.8 \%)$.

\section{Sexual behaviours and condom use}

Of all respondents, more than $94 \%$ identified themselves as homosexual or bisexual. Of participants $48.60 \%$ found their sexual partners through the internet and $22.87 \%$ from the park, public rest room and grass. Of them $57.20 \%$ had had a sexual debut with a man at over 22 years of age. In the previous 6 months, $80.77 \%$ had anal sex with one or two male partners, and $34.38 \%$ and $34.37 \%$ of participants had consistent condom use during anal sex with regular and irregular partners, respectively.

Of the participants, $65.11 \%$ reported ever having had sex with a woman, among whom $53.95 \%$ had their sexual debut with a woman at below 22 years of age. In the previous 6 months, $92.03 \%$ reported sex with no more than two female partners. The prevalence of consistent condom use with regular partners was $23.03 \%$, and $33.53 \%$ never used condom during risky behaviours.

Among the respondents, the prevalence of sexual behaviours related to money boys, group sex, alcohol or drug use was all under $10 \%$. Therefore our focus is on the prevalence of condom use with constant and provisional partners. Prevalence of consistent condom use during anal and oral sex was about $34 \%$ and $10 \%$, respectively (table 2 ).

\section{Logistic regression analysis}

We produced univariate logistic regression analysis for all factors in the questionnaire, and 15 of them turned out to be associated with HIV infection (table 3). Overall, the more frequently participants have sex (no matter who the partner is), the more likely it is for them to get infected; also, participants with lower educational level, better physical condition and older secondary male sexual partner were more likely to be HIV-positive. When compared with those whose primary sexual partner was infected with HIV, participants whose primary sexual partner was HIV-negative or of unclear HIV status were more likely to be HIV infected, while those who did not have medical insurance, who never had sex with a woman, who did not smoke or drink, who thought they were HIV-negative, who supported treatment of HIV infection and were syphilis-negative were less likely to be HIV-positive when compared with their HIV-negative counterparts.

Factors with $p$ value $<0.2$ in univariate logistic regression analysis were chosen for multivariate analysis (relationship with the recruiter, age of homosexual debut, suicide tendency and ever had test for HIV infection were factors with $p$ value $>0.05$ but $<0.2$ ). Table 4 shows the results of multivariate logistic regression analysis. Compared with those with primary education level or below, participants who finished college education were less likely to be infected by HIV. Participants who thought they were HIV-negative, who supported treatment, who were syphilis-negative and who never had heterosexual behaviour were less likely to be HIV-positive compared with their counterparts. Also, participants were more likely to be infected with HIV if their primary sexual partner's HIV status was negative or unclear, compared with those whose primary sexual partner was HIV-positive. 
Table 2 Sexual behaviour and condom use

\begin{tabular}{|c|c|c|c|}
\hline Variable & $\mathbf{N}$ & $\begin{array}{l}\text { Rough } \\
\text { prevalence } \\
(\%)\end{array}$ & $\begin{array}{l}\text { Adjusted } \\
\text { prevalence } \\
(\%)\end{array}$ \\
\hline \multicolumn{4}{|c|}{ Self-reported sex orientation } \\
\hline Homosexual & 625 & 47.53 & 43.82 \\
\hline Heterosexual & 10 & 0.76 & 1.05 \\
\hline Bisexual & 640 & 48.67 & 50.36 \\
\hline Indeterminate & 40 & 3.04 & 4.77 \\
\hline \multicolumn{4}{|l|}{ Venues } \\
\hline $\begin{array}{l}\text { Bar/disco/tearoom/ } \\
\text { club }\end{array}$ & 145 & 11.02 & 12.25 \\
\hline $\begin{array}{l}\text { Bath house/sauna/ } \\
\text { pedicure centre/ } \\
\text { massage parlour }\end{array}$ & 174 & 13.23 & 11.17 \\
\hline $\begin{array}{l}\text { Park/public rest } \\
\text { room/lawn }\end{array}$ & 294 & 22.36 & 22.87 \\
\hline Internet & 652 & 49.58 & 48.6 \\
\hline Others & 50 & 3.8 & 5.11 \\
\hline \multicolumn{4}{|c|}{ Age of first sex with a man (years) } \\
\hline$\leq 22$ & 626 & 47.64 & 42.8 \\
\hline$>22$ & 688 & 52.36 & 57.2 \\
\hline \multicolumn{4}{|c|}{ Anal sex with male partners (past 6 months) } \\
\hline Yes & 1141 & 86.7 & 81.54 \\
\hline No & 175 & 13.3 & 18.46 \\
\hline \multicolumn{4}{|c|}{ Number of male partners (past 6 months) } \\
\hline$\leq 2$ & 838 & 71.08 & 80.77 \\
\hline$>2$ & 341 & 28.92 & 19.23 \\
\hline
\end{tabular}

Condom use during anal sex with regular partners (past

6 months)

$\begin{array}{lrrr}\text { Never } & 8 & 0.71 & 0.81 \\ \text { Sometimes } & 11 & 0.98 & 0.41 \\ \text { Always } & 23 & 2.04 & 3.07 \\ \text { Had no such sex } & 1084 & 96.27 & 95.7\end{array}$

Condom use during anal sex with irregular partners (past 6 months)

$\begin{array}{lrrr}\text { Never } & 63 & 5.58 & 7.08 \\ \text { Sometimes } & 237 & 20.97 & 18.28 \\ \text { Always } & 39 & 3.46 & 4.38 \\ \text { Had no such sex } & 1057 & 93.87 & 93.12\end{array}$

Condom use during oral sex with regular partners (past

6 months)

$\begin{array}{lrcc}\text { Never } & 520 & 49.29 & 44.73 \\ \text { Sometimes } & 82 & 7.78 & 7.66 \\ \text { Always } & 89 & 8.44 & 10.82 \\ \text { Had no such sex } & 364 & 34.5 & 36.8\end{array}$

Condom use during oral sex with irregular male partners (past 6 months)

\begin{tabular}{lrlr} 
Never & 520 & 49.52 & 44.68 \\
Sometimes & 88 & 8.38 & 8.63 \\
Always & 83 & 7.9 & 9.47 \\
Had no such sex & 359 & 34.19 & 37.22 \\
Sex with a woman (ever) & & & \\
Yes & 804 & 61.14 & 65.11 \\
No & 511 & 38.86 & 34.89 \\
Age of first sex with a woman (years) & \\
$\leq 22$ & 450 & 56.03 & 53.95 \\
$>22 \%$ & 353 & 43.96 & 46.05 \\
Sex with female partner (past 6 & months) & \\
Yes & 387 & 48.68 & 53.15 \\
No & 408 & 51.32 & 46.85 \\
\hline \multicolumn{4}{r}{}
\end{tabular}

Table 2 Continued

\begin{tabular}{lrll}
\hline Variable & N & $\begin{array}{l}\text { Rough } \\
\text { prevalence } \\
\text { (\%) }\end{array}$ & $\begin{array}{l}\text { Adjusted } \\
\text { prevalence } \\
(\%)\end{array}$ \\
\hline Condom use with regular female partner & (past 6 months) \\
Never & 192 & 36.36 & 33.53 \\
Sometimes & 58 & 10.98 & 8.26 \\
Always & 87 & 16.48 & 23.03 \\
Had no such sex & 191 & 36.17 & 35.19 \\
\hline
\end{tabular}

\section{DISCUSSION}

To our knowledge, this study was the first large-scale research to assess the prevalence and associated risk factors of HIV among MSM in Zhejiang Province using the RDS method. Our findings reported that the prevalence of HIV and syphilis was $7.2 \%$ and $13.7 \%$, respectively. The rates of consistent condom use with male and female sexual partners were low and $75.41 \%$ of the participants did not know the HIV status of their primary sexual partner. Multivariate logistic regression analysis revealed that participants who thought they were HIV-negative, who supported treatment, who were syphilis-negative, who had a higher educational level, who never had heterosexual behaviour and whose primary sexual partner was HIV-positive were less likely to be infected by HIV compared with their counterparts, while frequency of sexual behaviour with primary sexual partner was positively associated with HIV infection. Confronting this case, this study provides more detailed evidence of HIV incidence in Zhejiang province and calls for innovative programmes to prevent the expansion of HIV/AIDS.

The HIV prevalence among MSM in Zhejiang province was $13.8 \%$, which was higher than the data from sentinel surveillance of any past year $(8.6 \%$ in 2011 was the highest before our study),${ }^{10-12}$ which may be due to the different representativeness of sampling between RDS and sentinel surveillance. The results of data sampled by RDS revealed the emergence of HIV prevalence among MSM, which calls for intensive attention for this population on intervention and treatment.

In our study, the adjusted prevalence of syphilis was $11.4 \%$ and was higher than the prevalence of HIV, which is similar to the results of other relevant studies in Guangzhou, China. ${ }^{24}$ The prevalence of co-infection of HIV and syphilis was $4.9 \%$, suggesting that syphilis is also a problem that needs attention among MSM. It is known that syphilis infection increases the risk of HIV infection, ${ }^{25}$ which is consistent with the multivariate analysis result of our study. This is probably because that the damage of anal mucosa generated by syphilis increases the probability of HIV infection during unsafe anal sex. Effectiveness of services for HIV and syphilis intervention need to be improved.

The role that sex with female partners might play in HIV transmission for MSM has been studied in many 
Table 3 Univariate analysis of factors associated with HIV infection among MSM

\begin{tabular}{|c|c|c|}
\hline Factors & OR & p Value \\
\hline \multicolumn{3}{|l|}{ Educational level } \\
\hline Primary school or below & 1.00 & \\
\hline Middle school & 0.55 & 0.015 \\
\hline High school/technical school & 0.38 & $<0.001$ \\
\hline College or above & 0.19 & $<0.001$ \\
\hline \multicolumn{3}{|l|}{ Medical insurance } \\
\hline Insured & 1.00 & \\
\hline Uninsured & 0.59 & 0.041 \\
\hline $\begin{array}{l}\text { Number of anal sex encounters in the } \\
\text { last } 6 \text { months }\end{array}$ & 1.88 & 0.011 \\
\hline $\begin{array}{l}\text { Number of oral sex encounters in the } \\
\text { last } 6 \text { months }\end{array}$ & 2.16 & 0.002 \\
\hline $\begin{array}{l}\text { Sex behaviour frequency with No.1 } \\
\text { sexual partner }\end{array}$ & 1.51 & 0.001 \\
\hline Physical condition & 1.52 & 0.003 \\
\hline \multicolumn{3}{|l|}{ HIV status of primary sexual partner } \\
\hline Positive & 1.00 & \\
\hline Negative & 6.82 & 0.031 \\
\hline Unclear & 11.70 & 0.004 \\
\hline Age of secondary sexual partner & 1.35 & 0.008 \\
\hline $\begin{array}{l}\text { Sex behaviour frequency with } \\
\text { secondary sexual partner }\end{array}$ & 1.38 & 0.027 \\
\hline \multicolumn{3}{|l|}{ Heterosexual behaviour } \\
\hline Yes & 1.00 & \\
\hline No & 0.36 & $<0.0001$ \\
\hline \multicolumn{3}{|l|}{ Smoking } \\
\hline Yes & 1.00 & \\
\hline No & 0.54 & $<0.0001$ \\
\hline \multicolumn{3}{|l|}{ Drinking } \\
\hline Yes & 1.00 & \\
\hline No & 0.77 & 0.049 \\
\hline \multicolumn{3}{|l|}{ Self-perceived possibility of HIV infection } \\
\hline Yes & 1.00 & \\
\hline No & 0.74 & 0.035 \\
\hline \multicolumn{3}{|c|}{ Attitude towards the treatment of HIV infection } \\
\hline Object & 1.00 & \\
\hline Support & 0.24 & 0.011 \\
\hline \multicolumn{3}{|l|}{ Syphilis infection } \\
\hline Positive & 1.00 & \\
\hline Negative & 0.32 & $<0.0001$ \\
\hline
\end{tabular}

researches. ${ }^{26}$ The mass opinion is that MSM who have sex with women have higher rates of HIV prevalence than those that have sex with only men. ${ }^{27}$ Our results also show that heterosexual behaviour increases the possibility of HIV infection, which is consistent with former researches. Of all respondents, $30.81 \%$ were married and over $50 \%$ had had sex with female partners, which indicated the bridge between MSM and the female general population. The rate of consistent condom use among MSM was low, thus high frequency of unsafe sexual behaviour with male and female partners among MSM contributes greatly to the rise of HIV incidence. Intervention services should cover MSM and their female sexual partners to get better effect.
Table 4 Multivariate analysis of factors associated with HIV infection among MSM

\begin{tabular}{lcc}
\hline Factors & OR & p Value \\
\hline Educational level & & \\
$\quad$ Primary school or below & 1.00 & \\
College or above & 0.32 & 0.026 \\
Self-perceived possibility of HIV & infection & \\
$\quad$ Yes & 1.00 & \\
$\quad$ No & 0.58 & $<0.001$ \\
Attitude towards the treatment of HIV infection & \\
$\quad$ Object & 1.00 & \\
$\quad$ Support & 0.32 & 0.029 \\
HIV status of primary sexual partner & & \\
Positive & 1.00 & \\
$\quad$ Negative & 10.17 & 0.020 \\
$\quad$ Unclear & 12.37 & 0.009 \\
Syphilis infection & 1.00 & \\
$\quad$ Positive & 0.31 & $<0.001$ \\
$\quad$ Negative & & \\
Heterosexual behaviour & 1.00 & \\
Yes & 0.51 & 0.011 \\
$\quad$ No & & \\
\hline MSM, men who have sex with men. &
\end{tabular}

Findings in this study revealed that nearly half (48.6\%) of the participants met their sexual partners through the internet. With the widespread use of computers, the internet has become a convenient medium for HIV transmission, especially among young and well educated MSM. ${ }^{28}$ The high prevalence of internet use for meeting sexual partners suggests that sexual networks may primarily be forming online. ${ }^{29}$ Previous studies indicate that it is more likely for HIV-positive gay men to get an STD infection when they find a sexual partner of the same status online rather than offline. ${ }^{30}$ On the other hand, MSM populations also seek help and acquire HIV-related knowledge through the internet; hence, new HIV primary prevention interventions online should be taken immediately to enhance the effectiveness of existing intervention programmes.

Multivariate analysis showed that participants who do not think they have HIV were less likely to be infected, which may indicate that MSM are willing to take protective measures as long as they are not infected by HIV or other STDs. Providing testing with more frequency and convenience can be beneficial to control the epidemic, for the self-protective awareness of MSM.

In this research, we used RDS to recruit participants and to assess the HIV/AIDS prevalence among MSM in Zhejiang province. In recent years, RDS has been widely adopted for behavioural and serological surveillance in populations at high risk, as these groups are often hard to reach. ${ }^{31}$ Compared with snowball sampling and other convenience sampling methods, RDS is a methodological advance for enrolling hidden subgroups through social networking. It maintains better control over the recruitment procedure by changing the number of seeds. 
Our study has several limitations. We reached the sample size of 1316 with a total of 24 seeds after more than 10 recruitment waves, which indicated a low coupon rate. Reason for the low coupon rate was not clear, probably due to the low activity and sociality of MSM in Zhejiang. Also, data collected by RDS requires unique statistical techniques and may have operational difficulties in some situations.

In summary, the alarmingly high HIV and syphilis prevalence, along with the existing multiple risk sexual behaviours and low prevalence of consistent condom use among MSM, presents a case for caution for the whole society. It is of great significance to implement and enhance comprehensive interventions targeting MSM and their sexual partners, as well as to build an advanced surveillance system to slow the spread of HIV effectively.

\section{Author affiliations}

${ }^{1}$ Center for Disease Control and Prevention of Zhejiang Province, Hangzhou, Zhejiang, China

${ }^{2}$ Department of Epidemiology \& Biostatistics, School of Public Health, Nanjing Medical University, Nanjing, Jiangsu, China

${ }^{3}$ Wenzhou Center for Disease Control and Prevention, Wenzhou, Zhejiang, China

${ }^{4}$ Hangzhou Center for Disease Control and Prevention, Hangzhou, Zhejiang, China

${ }^{5}$ Ningbo Center for Disease Control and Prevention, Ningbo, Zhejiang, China

Contributors XP, QM and SX were involved in the study design. HW, SZ, JC and $Y Z$ performed the experiments. WM, DM and LH analysed the data. $X Z$, TJ, HW and $Y X$ contributed reagents/materials/analysis tools. MW, WM and ZP wrote the paper. All authors read and approved the final manuscript.

Funding Priority Academic Program Development of Jiangsu Higher Education Institutions (PAPD); Key Project on Social Development among S\&T Major Project of Zhejiang Province, China (2013C03047-1); Department of $S$ and T for Social Development (2012ZX10001-001); National Natural Science Foundation of China (81001288).

Competing interests None declared.

Patient consent Obtained.

Provenance and peer review Not commissioned; externally peer reviewed.

Data sharing statement No additional data are available.

Open Access This is an Open Access article distributed in accordance with the Creative Commons Attribution Non Commercial (CC BY-NC 4.0) license, which permits others to distribute, remix, adapt, build upon this work noncommercially, and license their derivative works on different terms, provided the original work is properly cited and the use is non-commercial. See: http:// creativecommons.org/licenses/by-nc/4.0/

\section{REFERENCE}

1. UNAIDS. Report on the global AIDS epidemic-2010. Geneva: UNAIDS, 2010. http://www.unaids.org/globalreport/global_report.htm (accessed 27 Jul 2015).

2. Zhang B, Li X, Shi T, et al. A primary estimation of the number of population and HIV prevalence in homosexual and bisexual men in China. J China AIDS/STD Prev Control 2002;8:197.

3. Bongaarts J, Over M. Global HIV/AIDS policy in transition. Science 2010;328:1359-60.

4. Liu $\mathrm{H}$, Yang $\mathrm{H}$, Li X, et al. Men who have sex with men and human immunodeficiency virus/sexually transmitted disease control in China. Sex Transm Dis 2006;33:68-76.
5. Shang $\mathrm{H}, \mathrm{Xu} \mathrm{J}, \operatorname{Han} \mathrm{X}$, et al. HIV prevention: bring safe sex to China. Nature 2012;485:576-7.

6. NCAIDS, NCSTD, China CDC. Update on the AIDS/STD epidemic in China and main response in control and prevention in December, 2014. Chin J AIDS STD 2014;21:87. (Article in Chinese)

7. Gállego-Lezáun C, Arrizabalaga Asenjo M, González-Moreno J, et al. Syphilis in men who have sex with men: a warning sign for HIV infection. Actas Dermosifiliogr 2015. [Epub ahead of print]

8. Beyrer C, Baral SD, van Griensven F, et al. Global epidemiology of HIV infection in men who have sex with men. Lancet 2012;380:367-77.

9. Hong FC, Zhou H, Cai YM, et al. Prevalence of syphilis and HIV infections among men who have sex with men from different settings in Shenzhen, China: implications for HIV/STD surveillance. Sex Transm Infect 2009;85:42-4.

10. Center for Disease Control and Prevention of Zhejiang Province. Annual Report of HIV Epidemic Surveillance in Zhejiang Province, 2008. (Article in Chinese, not publicly published)

11. Center for Disease Control and Prevention of Zhejiang Province. Annual Report of HIV Epidemic Surveillance in Zhejiang Province, 2011. (Article in Chinese, not publicly published)

12. Center for Disease Control and Prevention of Zhejiang Province. Annual Report of HIV Epidemic Surveillance in Zhejiang Province, 2013. (Article in Chinese, not publicly published)

13. Choi KH, Liu H, Guo Y, et al. Emerging HIV-1 epidemic in China in men who have sex with men. Lancet 2003;361:2125-6.

14. He Q, Wang $\mathrm{Y}$, Lin $\mathrm{P}$, et al. Potential bridges for HIV infection to men who have sex with men in Guangzhou, China. AIDS Behav 2006;10:S17-23.

15. Kendall C, Kerr LR, Gondim RC, et al. An empirical comparison of respondent-driven sampling, time location sampling, and snowball sampling for behavioral surveillance in men who have sex with men, Fortaleza, Brazil. AIDS Behav 2008;12:97-104.

16. Magnani R, Sabin K, Saidel T, et al. Review of sampling hard-to-reach and hidden populations for HIV surveillance. AIDS 2005;19:S67-72.

17. Tang $\mathrm{W}$, Yang $\mathrm{H}$, Mahapatra $\mathrm{T}$, et al. Feasibility of recruiting a diverse sample of men who have sex with men: observation from Nanjing, China. PLOS ONE 2013;8:e77645.

18. Ma XY, Zhang QY, He X, et al. Epidemiological study on the status of HIV/STDs and relative behaviors among MSM in Beijing. Zhonghua Liu Xing Bing Xue Za Zhi 2007;28:851-5. (Article in Chinese)

19. Schonlau M, Liebau E. Respondent-driven sampling. Stata J 2012;12:72-93.

20. Johnston LG, Chen YH, Silva-Santisteban A, et al. An empirical examination of respondent driven sampling design effects among HIV risk groups from studies conducted around the world. AIDS Behav 2013;17:2202-10.

21. Salganik MJ. Variance estimation, design effects, and sample size calculations for respondent-driven sampling. J Urban Health 2006:83:98-112.

22. Radloff LS. The CES-D scale a self-report depression scale for research in the general population. Appl Psych meas 1977;1:385-401.

23. Besag J, York J, Mollié A. Bayesian image restoration, with two applications in spatial statistics. Ann Inst Stat Math 1991;43:1-20.

24. Zhou Y, Li D, Lu D, et al. Prevalence of HIV and Syphilis Infection among Men Who Have Sex with Men in China: a meta-analysis. Biomed Res Int 2014;2014:620431.

25. Lau JT, Hao C, Xu H, et al. Syphilis and HIV: problem and prevention. Int $J$ Infect Dis 2012;16:e62.

26. Lau JT, Lin C, Hao C, et al. Public health challenges of the emerging HIV epidemic among men who have sex with men in China. Public Health 2011;125:260-5.

27. Beyrer C, Trapence G, Motimedi F, et al. Bisexual concurrency, bisexual partnerships, and HIV among southern African men who have sex with men. Sex Transm Infect 2010;86:323-7.

28. Dapeng Zhang, Peng Bi, Fan Lv, et al. Internet use and risk behaviours: an online survey of visitors to three gay websites in China. Sex Transm Infect 2007:83:571-6.

29. Benotsch EG, Kalichman S, Cage M. Men who have met sex partners via the internet: prevalence, predictors, and Implications for HIV prevention. Arch Sex Behav 2002;31:177-183.

30. Bolding G, Davis M, Hart G, et al. Gay men who look for sex on the internet: is there more HIV/STI risk with online partners? AIDS 2005; 19:961-8.

31. Johnston LG, Khanam R, Reza M, et al. The effectiveness of respondent driven sampling for recruiting males who have sex with males in Dhaka, Bangladesh. AIDS Behav 2008;12:294-304. 